\title{
A Miniature 25-GHz 9-dB CMOS Cascaded Single-Stage Distributed Amplifier
}

\author{
Ming-Da Tsai, Student Member, IEEE, Kuo-Liang Deng, Huei Wang, Senior Member, IEEE, Chun-Hung Chen, \\ Chih-Sheng Chang, and John G. J. Chern
}

\begin{abstract}
A 25-GHz complementery metal oxide semiconductor (CMOS) cascaded single-stage distributed amplifier (CSSDA) using standard $0.18-\mu \mathrm{m}$ CMOS technology is presented in this letter. It demonstrates the highest gain-bandwidth product (GBP) with smallest chip area reported for a fully-integrated CMOS wideband amplifier using a standard $\mathrm{Si}$-based integrated circuit process. The chip size including testing pads is only $0.36 \mathrm{~mm}^{2}$, and the ratio of GBP to chip size achieves $552 \mathrm{GHz} / \mathrm{mm}^{2}$. This circuit is the first CSSDA realized in CMOS technology, and represents state-of-the-art performances.
\end{abstract}

Index Terms-Complementary metal oxide semiconductor (CMOS), distributed amplifier, helical inductor, microwave monolithic integrated circuit (MMIC).

\section{INTRODUCTION}

D ISTRIBUTED circuits can defy some of the performance trade-offs in conventional circuits by taking advantage of multiple parallel signal paths. A distributed amplifier has a more relaxed gain-bandwidth trade-off than a conventional amplifier since the parasitic capacitances of the transistor are absorbed into the transmission lines or the LC ladder filter to become part of the passive network. Table I summarizes the recently reported performances of complementery metal oxide semiconductor (CMOS) broadband amplifiers compared with this work [1]-[9]. Using the 0.6- $\mu \mathrm{m}$ CMOS process, a fully integrated DA using on-chip planar spiral inductors achieves a measured pass-band gain of $6.1 \mathrm{~dB}$ with $5.5-\mathrm{GHz}$ unity-gain bandwidth [1]. On the other hand, a fully differential DA achieves 5.5-dB pass-band gain and $8.5-\mathrm{GHz}$ unity gain bandwidth [2]. Using a silicon-on-sapphire (SOS) n-type metal oxide semiconductor field effect transistor (n-MOSFET) process to avoid the substrate loss, a DA with a bandwidth of $10 \mathrm{GHz}$ and $5-\mathrm{dB}$ gain was demonstrated in a $0.5-\mu \mathrm{m}$ SOS n-MOSFET (NMOS) process [3]. For DAs using 0.18- $\mu \mathrm{m}$ CMOS process, a three stage DA designed with coplanar strip

Manuscript received February 1, 2004; revised March 18, 2004. This work was supported in part by the NTU-TSMC Joint-Development Project and the National Science Council under Contracts NSC 92-2213-E-002-069 and NSC 93-2752-E-002-002-PAE. The review of this letter was arranged by Associate Editor A. Stelzer.

M.-D. Tsai and H. Wang are with the Department of Electrical Engineering and Graduate Institute of Communication Engineering, National Taiwan University, Taipei 10617, Taiwan, R.O.C. (e-mail: r90042@ew.ee.ntu.edu.tw; hueiwang@ew.ee.ntu.edu.tw).

K.-L. Deng was with the Department of Electrical Engineering and Graduate Institute of Communication Engineering, National Taiwan University, Taipei 10617, Taiwan, R.O.C., and he is now with Taiwan Semiconductor Manufacturing Company, Hsinchu, Taiwan, R.O.C.

C.-H. Chen, C.-S. Chang, and J. G. J. Chern are with the Taiwan Semiconductor Manufacturing Company, Hsinchu, Taiwan, R.O.C.

Digital Object Identifier 10.1109/LMWC.2004.837387 lines demonstrated a low frequency gain of $5 \mathrm{~dB}$, sloping down to $1 \mathrm{~dB}$ at $15 \mathrm{GHz}$ [4], two DAs using high impedance coplanar waveguides as inductive elements demonstrated 8 and 10-dB gain up to $10 \mathrm{GHz}$, respectively [5], and DAs of 14-GHz and 22-GHz bandwidth were also demonstrated in [6], [7]. The highest operation frequency of DA using $100-\mathrm{GHz}$ $f_{\text {MAX }}$ 0.18- $\mu \mathrm{m}$ CMOS technology based on modified source degeneration (parallel RC network) achieved 4-dB gain and 39-GHz bandwidth [8], and a 27-GHz CPW 0.18- $\mu \mathrm{m} \mathrm{CMOS}$ DA had a measured gain of $6 \mathrm{~dB}$ [9]. A fully integrated conventional DA, however, suffers the disadvantage of huge chip size. Another type of distributed circuit called cascaded single-stage distributed amplifier (CSSDA) in CMOS technology were also presented their simulation results but no measurement data were demonstrated [10], [11]. A CSSDA with huge chip size has also been proposed to achieve wide bandwidth and realized in GaAs HEMTs or hybrid circuits [12], [13].

In this letter, a miniature CSSDA based on cascade configuration and monolithic helical inductors using a commercial CMOS process is first demonstrated. The gain-bandwidth product of our miniature chip is believed to be the highest among the recently published results for CMOS distributed amplifiers. The chip size including testing pads is only $0.75 \times 0.48 \mathrm{~mm}$, and the ratio of GBP to chip size achieves $552 \mathrm{GHz} / \mathrm{mm}^{2}$. This circuit is the first CSSDA realized in CMOS technology, and represents state-of-the-art performances.

\section{CiRCUIT DESIGN AND FABRICATION}

In the design of wideband distributed amplifiers, artificial transmission lines can be realized by multiorder LC ladder network. In conjunction with active devices connected in parallel, the parasitic capacitance of active devices is absorbed into the LC ladder network. The inductor can be realized with transmission lines or spiral inductors [1]-[9]. However, the drawback is large die size. In order to reduce chip size, the inductance of the artificial transmission line is realized with helical inductors. Helical inductor occupies less chip area than that of planar spiral since the turn is expanded vertically as shown in Fig. 1(a). Usually, top metal is thicker than the lower metal layers, and thus $Q$-factor of helical inductor would be lower than that of planar spiral inductor. However, the area occupation of helical inductor is much smaller. Furthermore, smaller area gives smaller substrate loss, so only little performance degradation of the helical inductor over the planar spiral inductor in circuit is prospective [14]. For example, a 2-nH of helical inductor can achieve peak quality factor of eight at $5 \mathrm{GHz}$ and self-resonance frequency of $16 \mathrm{GHz}$ [15]. 
TABLE I

ReCENTLy RePorted Performance of CMOS Distributed AMPlifier. SOS: Silicon-ON-SAPPhire. CPW: Coplanar WaVEGUide. CPS: Coplanar Strip Lines. CC: CASCODE CONFIGURATION. DC Bias USING Bias-T

\begin{tabular}{|c|c|c|c|c|c|c|c|c|c|}
\hline Process & $\begin{array}{c}\text { Bandwidth } \\
\text { (GHz) }\end{array}$ & Gain $(\mathrm{dB})$ & $\begin{array}{l}\text { Chip Area } \\
\left(\mathrm{mm}^{2}\right)\end{array}$ & $\begin{array}{c}\mathrm{GBP} \\
(\mathrm{GHz})\end{array}$ & $\begin{array}{c}\text { GBP/ ChipArea } \\
\left(\mathrm{GHz} / \mathrm{mm}^{2}\right)\end{array}$ & $\begin{array}{c}\text { Unit Gain } \\
\text { Freq. }(\mathrm{GHz})\end{array}$ & $\begin{array}{c}P_{\mathrm{DC}} \\
(\mathrm{mW})\end{array}$ & Chip Features & Ref. \\
\hline $\begin{array}{l}0.6 \mu \mathrm{m} \\
\mathrm{CMOS}\end{array}$ & 4 & 6.5 & 1.12 & 18 & 16 & 5.5 & 83.4 & Spiral inductors & {$[1]$} \\
\hline $\begin{array}{l}0.6 \mu \mathrm{m} \\
\mathrm{CMOS}\end{array}$ & 7.5 & 5.5 & 2.86 & 27 & 9 & 8.5 & 216 & $\begin{array}{c}\text { Fully differentiral, } \\
\text { Spiral inductors } \\
\end{array}$ & [2] \\
\hline $\begin{array}{c}0.5 \mu \mathrm{m} \\
\text { SOS MOS } \\
\end{array}$ & 10 & 5 & - & - & - & - & - & CPW & [3] \\
\hline $\begin{array}{c}0.18 \mu \mathrm{m} \\
\mathrm{CMOS}\end{array}$ & - & 5 & 0.45 & - & - & 23 & $90 *$ & CPS & [4] \\
\hline $\begin{array}{c}0.18 \mu \mathrm{m} \\
\mathrm{CMOS}\end{array}$ & 10 & 8 & 2.34 & 63 & 27 & - & - & $\begin{array}{c}\text { Darlington CC., } \\
\text { CPW }\end{array}$ & [5] \\
\hline $\begin{array}{c}0.18 \mu \mathrm{m} \\
\mathrm{CMOS}\end{array}$ & 22 & 7.3 & 1.35 & 118 & 88 & 24 & $52 *$ & $\begin{array}{c}\text { CC., } \\
\text { Spiral inductors }\end{array}$ & {$[6]$} \\
\hline $\begin{array}{l}0.18 \mu \mathrm{m} \\
\mathrm{CMOS}\end{array}$ & 14 & 10.6 & 1.6 & 161 & 100 & 18.5 & $52 *$ & $\begin{array}{c}\mathrm{CC} ., \\
\text { Spiral inductors }\end{array}$ & [7] \\
\hline $\begin{array}{c}0.18 \mu \mathrm{m} \\
\mathrm{CMOS}\end{array}$ & 39 & 4 & 3.3 & 98 & 30 & 39 & 140 & $\begin{array}{l}\text { RC degeneration, } \\
\text { Microstrip line }\end{array}$ & [8] \\
\hline $\begin{array}{c}0.18 \mu \mathrm{m} \\
\mathrm{CMOS}\end{array}$ & 27 & 6 & 1.62 & 107 & 66 & 29 & 68 & CC., CPW & [9] \\
\hline $\begin{array}{c}0.18 \mu \mathrm{m} \\
\mathrm{CMOS}\end{array}$ & 25 & 9 & 0.36 & 199 & 552 & 28 & 60 & $\begin{array}{l}\text { CSSDA CC., } \\
\text { Helical inductors }\end{array}$ & $\begin{array}{l}\text { This } \\
\text { work }\end{array}$ \\
\hline
\end{tabular}

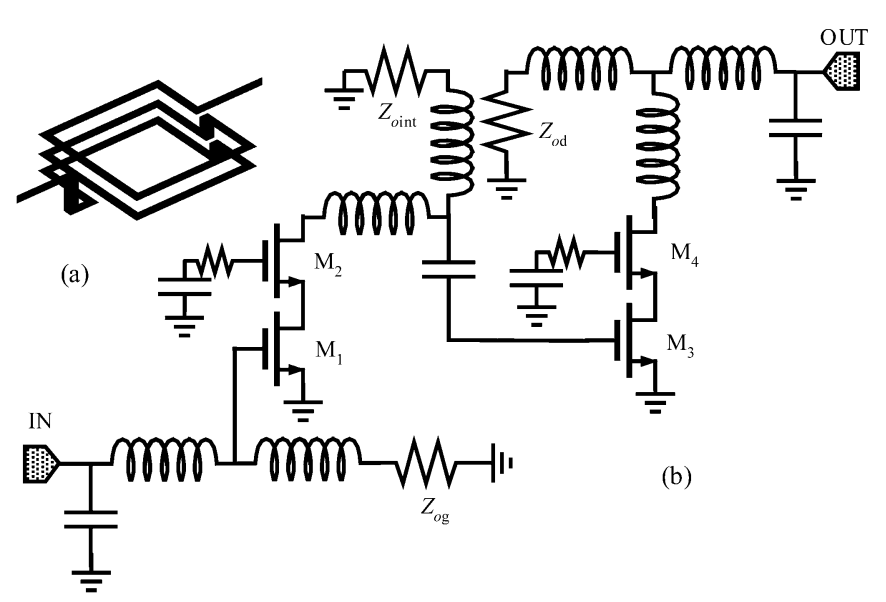

Fig. 1. (a) Cross-sectional view of helical inductor. (b) Simplified circuit schematic of cascaded single-stage distributed amplifier (CSSDA).

The schematic of the CMOS CSSDA is shown in Fig. 1(b). It consists of an input, output, and interstage transmission lines formed by using lumped helical inductors, coupled through the transconductance of the MOSFETs. The intrinsic gate and drain resistance $\left(R_{d s}\right)$ would increase the loss of the artificial transmission line and thus degrade the gain and bandwidth. In this study, the cascade configuration is used for the gain cells. The cascade gain cell can increase the drain resistance and reduce the loading in transmission line, also has higher maximum available gain compared to a common-source FET. The cascade devices of this design employ a $20-\Omega$ damping resistor in the gate of common-gate transistor to improve the high frequency stability.

Since the characteristic impedance of the inter-stage artificial transmission line $\left(Z_{\text {oint }}\right)$ can be different from the input and output impedance, it shows that the gain can be increased by the gate voltage of the inter-stage transmission line with increasing $Z_{\text {oint }}[12]$. With the target gain and bandwidth, the increasing

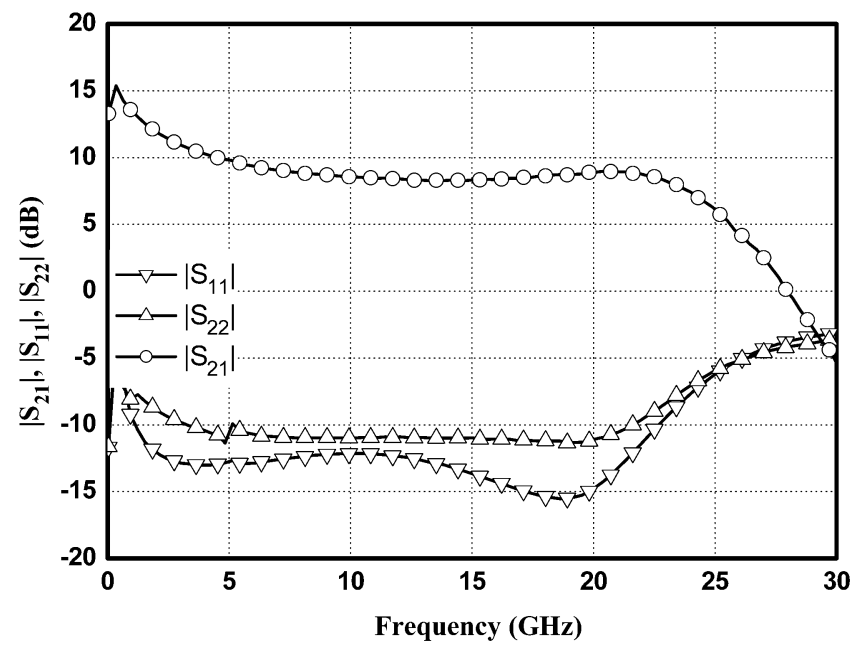

Fig. 2. Measured small signal gain and I/O return losses.

$Z_{\text {oint }}$ also can reduce the required gain stages and reduce chip area.

In this circuit, only two stages are used. The helical inductors were simulated with a full-wave EM simulator to ensure the model accuracy. The MMIC micrograph is shown in Fig. 4 with a chip size of $0.36 \mathrm{~mm}^{2}$ including testing pads. The chip is fabricated by TSMCs $0.18-\mu \mathrm{m}$ MS/RF technology [16], [17], with a $2-\mu \mathrm{m} \mathrm{AlCu}$ top metal layer. The substrate conductivity is approximately $10 \mathrm{~S} / \mathrm{m}$. With optimized CMOS technology and deep n-well, this technology provides a $f_{T}$ and $f_{\max }$ of better than 60 and $55 \mathrm{GHz}$, respectively.

\section{EXPERIMENTAL RESULTS}

The CMOS CSSDA chip was tested via on-wafer probing. Fig. 2 shows the measured gain $\left(\left|S_{21}\right|\right)$, and return losses $\left(\left|S_{11}\right|\right.$ and $\left.\left|S_{22}\right|\right)$. The power gain is about $9 \mathrm{~dB}$ with a $3-\mathrm{dB}$ frequency 


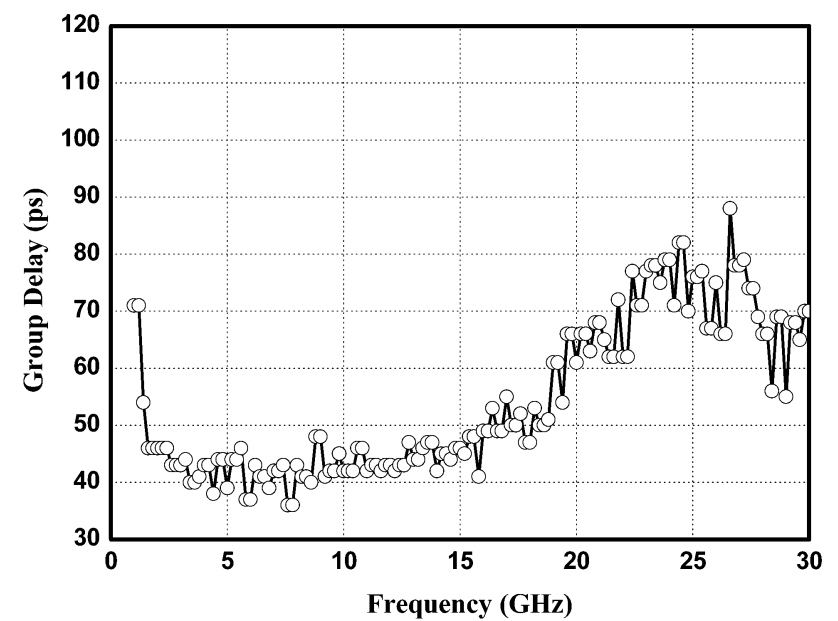

Fig. 3. Measured group delay.

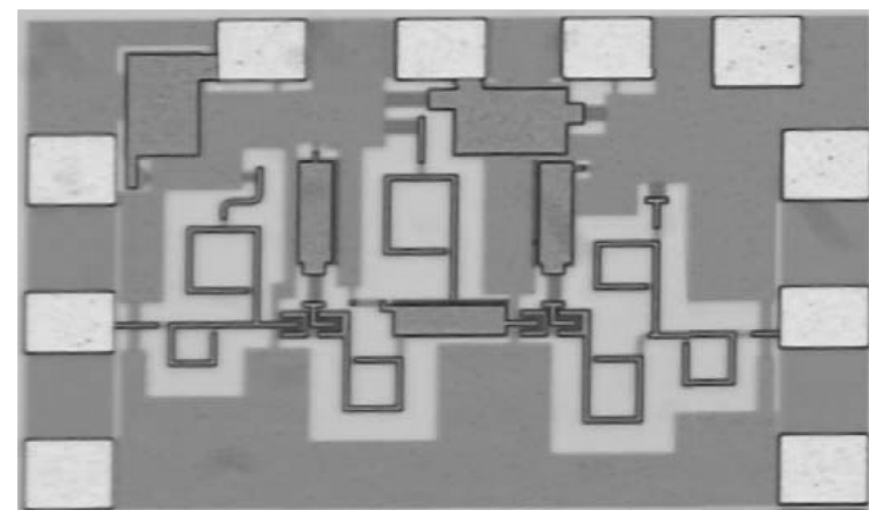

Fig. 4. Microphotograph of the CMOS CSSDA with a chip size of $0.75 \times$ $0.48 \mathrm{~mm}$ (including testing pads).

band up to $25 \mathrm{GHz}$, and return losses are better than $8 \mathrm{~dB}$. The measured $S$-parameters results agree with the simulated results reasonably. The measured group delay, as shown in Fig. 3, is about 45 ps with variation of 30 ps from 1 to $20 \mathrm{GHz}$. The measured output $P_{1 \mathrm{~dB}}$ is $-0.5 \mathrm{dBm}$ at $10 \mathrm{GHz}$. The two-tone test result shows that the output IP3 is about $8 \mathrm{dBm}$ at $10 \mathrm{GHz}$. The supply voltage is $3.5 \mathrm{~V}$ and consumes $17 \mathrm{~mA}$. Although the dc bias current goes through termination resistors, the total power consumption $(60 \mathrm{~mW})$ is still comparable with those of the reported DAs using bias-T to supply drain voltages [4], [6], [7]. The overall performance rivals the recently published results reported for CMOS distributed amplifiers.

\section{CONCLUSION}

A fully integrated CSSDA has been designed, fabricated and tested. This CMOS CSSDA demonstrated 9-dB gain and
25-GHz bandwidth, which indicates the highest gain-bandwidth product of reported to date for broadband CMOS amplifiers. The highest gain-bandwidth product is also achieved in only $0.36 \mathrm{~mm}^{2}$ chip area. This amplifier has potential for the signal amplification for the receiver in the optical communication application. Since this CSSDA was fabricated using a commercial $0.18-\mu \mathrm{m}$ CMOS technology, it can be easily integrated with other front-end circuits to build CMOS transceivers without requiring any additional masks or post-processing steps.

\section{REFERENCES}

[1] B. M. Ballweber, R. Gupta, and D. J. Allstot, "A fully integrated 0.5-5.5-GHz CMOS distributed amplifier," IEEE J. Solid State Circuits, vol. 35, pp. 231-239, Feb. 2000.

[2] H. Ahn and D. J. Allstot, "A 0.5-8.5-GHz fully differential CMOS distributed amplifier," IEEE J. Solid State Circuits, vol. 37, pp. 985-993, Aug. 2002.

[3] P. F. Chen et al., "Silicon-on-sapphire MOSFET distributed amplifier with coplanar waveguide matching," in Proc. IEEE RFIC Symp., 1998, pp. 161-164.

[4] B. Kleveland et al., "Monolithic CMOS distributed amplifier and oscillator," in Proc. IEEE Int. Solid-State Circuits Conf., 1999, pp. 70-71.

[5] B. M. Frank, A. P. Freundorfer, and Y. M. M. Antar, "Performance of $1-10-\mathrm{GHz}$ traveling wave amplifiers in 0.18- $\mu \mathrm{m}$ CMOS," IEEE Microwave Wireless Compon. Lett, vol. 12, pp. 327-329, Sept. 2002.

[6] R. C. Liu, K. L. Deng, and H. Wang, "A 0.6-22-GHz broadband CMOS distributed amplifier," in Proc. IEEE RFIC Symp., 2003, pp. 13-106.

[7] R. C. Liu, C. S. Lin, K. L. Deng, and H. Wang, "A 0.5-14-GHz 10.6-dB CMOS cascode distributed amplifier," in Proc. IEEE VLSI Circuits Symp., 2003, pp. 139-140.

[8] H. Shigematsu, M. Sato, T. Hirose, F. Brewer, and M. Rodwell, " 40 GB/s CMOS distributed amplifier for fiber-optic communication systems," in Proc. IEEE Int. Solid-State Circuits Conf., 2004, pp. 476-477.

[9] R. E. Amaya, N. G. Tarr, and C. Plett, "A $27 \mathrm{GHz}$ fully integrated CMOS distributed amplifier using coplanar waveguide," in Proc. IEEE RFIC Symp., 2004, pp. 193-196.

[10] A. Worapishet, M. Chongcheawchamnan, and S. Srisathit, "Broadband amplification in CMOS technology using cascaded single-stage distributed amplifier," Electron. Lett., vol. 38, pp. 675-676, July 2002.

[11] - "On the feasibility of cascaded single-stage distributed amplifier topology in digital technology," in Proc. IEEE Midwest Symp. Circuits Systems, 2002, pp. 354-257.

[12] B. Y. Banyamin and M. Berwick, "Analysis of the performance of fourcascaded single-stage distributed amplifiers," IEEE Trans. Microwave Theory Tech., vol. 48, pp. 2657-2663, Dec. 2000.

[13] K. L. Deng, T. W. Huang, and H. Wang, "Design and analysis of novel high-gain and broad-band GaAs pHEMT MMIC distributed amplifiers with traveling-wave gain stages," IEEE Trans. Microwave Theory Tech., vol. 51, pp. 2188-2196, Nov. 2003.

[14] J. Gil, S. S. Song, H. Lee, and H. Shin, "A $-119.2 \mathrm{dBc} / \mathrm{Hz}$ at $1 \mathrm{MHz}$, $1.5 \mathrm{~mW}$, fully integrated, $2.5-\mathrm{GHz}, \mathrm{CMOS}$ VCO using helical inductors," IEEE Microwave Wireless Compon. Lett., vol. 13, pp. 457-459, Nov. 2003.

[15] M. D. Tsai, "Design of 5-GHz low-voltage and gain-controllable CMOS low noise amplifier," M.S. thesis, Nat. Taiwan Univ., Taipei, Taiwan, R.O.C., 2003.

[16] H. M. Hsu et al., "A $0.18-\mu \mathrm{m}$ foundry RF CMOS technology with 70-GHz Ft for single chip system solutions," in IEEE Int. Microwave Symp. Dig., 2001, pp. 1869-1872.

[17] C. H. Diaz et al., "A $0.18-\mu \mathrm{m}$ CMOS logic technology with dual gate oxide and low-k interconnect for high-performance and low-power applications," in Proc. IEEE VLSI Technical Symp., 1999, pp. 11-12. 